\title{
Attitudes towards industry-sponsored
}

\section{publications}

Sek Ying Chair RN; PhD, Director and Professor, The Nethersole School of Nursing, The Chinese University of Hong Kong. Hong Kong SAR.

Qun Wang RN; PhD, Postdoctoral Fellow, The Nethersole School of Nursing, The Chinese University of Hong Kong. Hong Kong SAR.

Key Words: industry-sponsored publications publication ethics

E-mail: sychair@cuhk.edu.hk

\section{SUMMARY}

- There is an increasing tendency in industry-sponsored research, which has contributed to improvements in the quality of clinical research and knowledge transfer.

- $\quad$ Although there has been a debate on the validity of industrysponsored research and the publications, most medical/ nursing journals with high impacts have acceptable attitudes towards industry-sponsored publications.

- It is suggested that Connect: The World of Critical Care Nursing accepts papers with high quality and validity, no matter they are industry-sponsored papers or not, and require disclosure of funding and conflict of interest.

\section{INTRODUCTION}

The publication derived from clinical trials research is an important indicator of prestige and advancement among academics (McHenry, 2010). There is an increasing tendency in industry-sponsored clinical trials/research. In the United States, the industry spent $\$ 77.58$ billion on health and medical research in the year of 2011 , accounting for $56.94 \%$ of the total expenditures (Research!America, 2011). Accordingly, the amount of publications derived from the industry-sponsored research is increasing. With the collaboration between industry and academia, the industry-sponsored research has early access to cutting edge technologies and specialized skills, contributing to the high quality of the research. Moreover, it has efficient approach to transferring the study findings into products and applying in clinical practices (Pronk et al., 2015). Every coin has two sides. In spite of these advantages, there has been a debate on the validity of industry-sponsored research and the publications.

Previous systematic reviews revealed industry-sponsored publications were associated with more favorable results to sponsors' product (Bekelman \& Gross, 2003; Schott, 2010; Simondo, 2008). However, a recent systematic review in Cochrane Library compared the methodology of the industry-sponsored publications with those non-industry-sponsored ones (Lundh et al., 2012). No significant difference was revealed in sequence generation, allocation concealment, and follow up between the two types of publications. Moreover, industry-sponsored studies even performed better in blinding, and revealed less agreement between the results and the conclusions. Therefore, the more favorable results and conclusions in industry-sponsored publications could not be ascribed to their bias in methodology.

\section{ATTITUDES OF DIFFERENT JOURNALS}

To better understand the attitude of publishers towards industrysponsored publications, a comprehensive search was conducted among the top 100 , according to impact factor, medical and nursing journals in the Thomson Reuters Journal Citation Report. Out of the 100 medical journals, 97 journals do accept industry-sponsored publications, and two journals do not provide clear statement on this issue. Only the Tabacco Control under BMJ will not consider for publication papers reporting work funded, in whole or in part, by a tobacco company or tobacco industry organization. (Tobacco Control, 2016). As to the nursing journals, 93 out of searched 100 journals accept industry-sponsored publications and none clearly states rejection. Most of these journals that will accept industrysponsored publications require clear disclosure of funding and ask all the authors to declare any conflict of interest. Therefore, current journals concern more about the quality of the publications, rather than the source of funding.

\section{SUGGESTIONS FOR CONNECT}

Since the majority of journals with high impact factors accepts industry-sponsored papers, it is suggested that the journal of Connect: The World of Critical Care, accept this kind of paper. As an international and peer-reviewed journal providing a forum for practitioners to share good practice and research, manuscripts that have an impact on patient outcomes and practice innovations should be accepted including industrial papers. One of the founding principles of Connect: The World of Critical Care is to support advancement of the critical care nursing specialty. As discussed previously, industry-sponsored research may contribute to improvements and knowledge transfer in clinical practice and specialty development. Disseminating the study findings would improve the quality of care and patient outcomes. Therefore, Connect: The World of Critical Care should keep the possibility of accepting publications with industry sponsorship. At the same time, the journal must be alert of the validity of these manuscripts, especially those with favorable results to their sponsors' product.

The quality and validity of the papers are the fundamental elements to be considered for publishing in Connect: The World of Critical Care. To ensure the quality of publications, not limited to those industrysponsored papers, the journal should take further measures. Firstly, clear disclosure of funding should be requested and requirement on disclosure conflict of interest should be set as compulsory in the guidelines for authors. All authors must disclose any financial and personal relationships with other people or organizations that could influence their work. Secondly, the journal could adopt the 
recommendations from International Committee of Medical Journal Editors (ICMJE), a small working group of general medical journal editors. The ICMJE Form for Disclosure of Potential Conflicts of Interest could also be employed for Connect: The World of Critical Care (Appendix 1).

\section{CONCLUSIONS}

In conclusion, the industry-sponsored research has contributed to improvements in research and to knowledge transfer in clinical practice. Following the aims of the journal, it is suggested that Connect: The World of Critical Care, accept papers with high quality and validity, no matter they are industry-sponsored papers or not, and at the same time set clear requirements in disclosure of funding and conflict of interest.

\section{REFERENCES}

Bekelman JE, Li Y, Gross CP (2003). Scope and impact of financial conflicts of interest in biomedical research: a systematic review. JAMA 289(4), 454-465.

Committee on Publication Ethics (2016). Code of conduct for editors. [online]. Available at: http://publicationethics.org/files/u2/ New_Code.pdf. Accessed on Jul 15, 2016.

McHenry L (2010). Of sophists and spin-doctors: industrysponsored ghostwriting and the crisis of academic medicine. Mens Sana Monographs 8(1), 129.

Pronk JT, Lee SY, Lievense J, Pierce J, Palsson B, Uhlen M, Nielsen J (2015). How to set up collaborations between academia and industrial biotech companies. Nature Biotechnology 33(3), 237-240.

Recommendations of International Committee of Medical Journal Editors (2016). [online]. Available at: http://www.icmje.org/ recommendations/. Accessed 15 July 2016.

Research!America. (2011). US investment in health research. [online]. Available at: http://www.researchamerica.org/uploads/ healthdollar11.pdf. Accessed 14 July 2016.

Schott G, Pachl H, Limbach U, Gundert-Remy U, Ludwig WD, Lieb K (2010). The financing of drug trials by pharmaceutical companies and its consequences. Dtsches Arzteblatt International 107, 279-285.

Sismondo S (2008). Pharmaceutical company funding and its consequences: a qualitative systematic review. Contemporary Clinical Trials 29(2), 109-113.

Tobacco Control - Instructions for Authors (2016). [online]. Available at: http://tobaccocontrol.bmj.com/site/about/guidelines.xhtml. Accessed 15 July 2016.

\section{APPENDIX 1}

Appendix 1. Disclosure form of potential conflicts of interest

Instructions: The purpose of this form is to provide readers of your manuscript with information about your related interests that may potentially influence how they receive and understand your work. Each author should submit a separate form and is responsible for the accuracy and completeness of the submitted information.

Section 1. Identification information

- $\quad$ Given name; surname; date; corresponding author's name; manuscript title

Section 2. Work under consideration for publication

Did you or your institution at any time receive payment or services, either directly or indirectly (via your institution), from a third party (government, commercial, private foundation, etc.) for any aspect of the submitted work (including but not limited to grants, data monitoring board, study design, manuscript preparation, statistical analysis, etc.)?
Are there any relevant conflicts of interest? YES/NO

Notes: Checking "No" means that you did the work without receiving any financial support from any third party -- that is, the work was supported by funds from the same institution that pays your salary and that institution did not receive third-party funds with which to pay you. If yes, please provide the appropriate information below. Add a row if you have more than one.

- Name of institution/company; grant; personal fees; non-financial support; others; comments

Section 3. Relevant financial activities outside the submitted work

Place a check in the appropriate boxes in the table to indicate whether you have financial relationships (regardless of amount of compensation) with entities as described in the instructions. Use one line for each entity; add as many lines as you need. Relationships that were present during the 36 months prior to publication should also be reported.

- $\quad$ Are there any relevant conflicts of interest? YES/NO

If yes, please provide the appropriate information below. Add a row if you have more than one.

- Name of institution/company; grant; personal fees; non-financial support; others; comments

Notes: You should disclose interactions with ANY entity that could be considered broadly relevant to the work. Report all sources of revenue paid (or promised to be paid) directly to you or your institution or your family \& friends over the 36 months prior to submission of the work. This should include all monies from sources with relevance to the submitted work, not just monies from the entity that sponsored the research. Please note that your interactions with the work's sponsor that are outside the submitted work should also be listed here. If there is any question, it is usually better to disclose a relationship than not to do so. For grants you have received for work outside the submitted work, you should disclose support ONLY from entities that could be perceived to be affected financially by the published work, such as drug companies, or foundations supported by entities that could be perceived to have a financial stake in the outcome. Public funding sources, such as government agencies, charitable foundations or academic institutions, need not be disclosed.

Section 4. Intellectual property - patents and copyrights

- Do you have any patents, whether planned, pending or issued, broadly relevant to the work? YES/NO

If yes, please provide the appropriate information below. Add a row if you have more than one entity.

- $\quad$ Patent; pending; issued; licensed; royalties; licensee; comments

Section 5. Relationships not covered above

Are there other relationships or activities that readers could perceive to have influenced, or that give the appearance of potentially influencing, what you wrote in the submitted work?

- YES: the following relationships/conditions/circumstances are present (explain below):

- NO: other relationships/conditions/circumstances that present a potential conflict of interest

At the time of manuscript acceptance, journals will ask authors to confirm and, if necessary, update their disclosure statements. On occasion, journals may ask authors to disclose further information about reported relationships.

Definitions of terms

Entity: government agency, foundation, commercial sponsor, academic institution, et cetera; Grant: A grant from an entity, generally [but not always] paid to your organization; Personal fees: Monies paid to you for services rendered, generally honoraria, royalties, or fees for consulting, lectures, speakers bureaus, expert testimony, employment, or other affiliations; Nonfinancial support: Examples include drugs/equipment supplied by the entity, travel paid by the entity, writing assistance, administrative support, et cetera; Other: Anything not covered under the previous three boxes; Pending: The patent has been filed but not issued; Issued: The patent has been issued by the agency; Licensed: The patent has been licensed to an entity, whether earning royalties or not; Royalties: Funds are coming in to you or your institution due to your patent.

Reference

International Committee of Medical Journal Editors (2016). [online]. Available at: http://www.icmje.org/conflicts-of-interest/. Accessed 15 November 2016. 